\title{
Trade Efficiency Under FTA for Thailand's Agricultural Exports: Copula-based Gravity Stochastic Frontier Model
}

\section{Arisara Romyen ( $\square$ arisara.r@psu.ac.th )}

Prince of Songkla University - Hat Yai Campus: Prince of Songkla University https://orcid.org/00000002-9030-2445

\section{Chonrada Nunti}

Chiang Mai University

\section{Paramin Neranon}

Prince of Songkla University - Hat Yai Campus: Prince of Songkla University

\section{Research}

Keywords: Trade Efficiency, Free Trade Agreements, Autocorrelated Inefficiency Component, Copula-based Gravity Stochastic Frontier model, Thailand's trade potential

Posted Date: February 17th, 2022

DOI: https://doi.org/10.21203/rs.3.rs-1185170/v1

License: (9) This work is licensed under a Creative Commons Attribution 4.0 International License. Read Full License 


\title{
Trade Efficiency under FTA for Thailand's Agricultural Exports: Copula-based Gravity Stochastic Frontier Model
}

\author{
Arisara Romyen ${ }^{1 *}$, Chonrada Nunti ${ }^{2}$, and Paramin Neranon ${ }^{3}$ \\ 1, * Department of Agribusiness Economics and Management, Faculty of Economics, Prince of Songkla \\ University, Thailand. Email: arisara.r@psu.ac.th (* Corresponding Author) \\ ${ }^{2}$ Faculty of Economics, Chiang Mai University, Thailand. Email: chonradanunti@gmail.com \\ ${ }^{3}$ Department of Mechanical and Mechatronics Engineering, Faculty of Engineering, Prince of Songkla \\ University, Thailand. Email: paramin.n@psu.ac.th
}

\begin{abstract}
This study investigated the trade effects of Free Trade Agreements (FTAs) between Thailand and its trading partners. The important agricultural commodities rubber, cassava, fruit, vegetables and herbs were assessed from 1998 to 2019. In a traditional stochastic frontier model the two error components, of symmetric noise $\left(v_{j}\right)$ and a non-negative inefficiency $\left(u_{j}\right)$ are assumed to be independent. This may result in invalid inferences due to misspecification. To address this obstacle, Copula-based Gravity Stochastic Frontier models using panel criteria were constructed to estimate trade efficiency. Empirically, the Student t copula-based SFM minimizes both AIC and BIC. According to their mean TE, China and Japan had the highest export efficiencies (0.48) followed by India (0.41), New Zealand (0.39) and Australia (0.33) in rank order. Hence, Thailand should pursue more FTA negotiations with the trading partners. Moreover, they should promote miscellaneously behind-the-border barriers to stimulate flows of goods to enhance the country's trade efficiency substantially.
\end{abstract}

Keywords: Trade Efficiency, Free Trade Agreements, Autocorrelated Inefficiency Component, Copula-based Gravity Stochastic Frontier model, Thailand's trade potential

JEL Classification Code: F02, F13, F15, F41 


\section{Introduction}

Thailand is an export-oriented economy with exports accounting for approximately $65 \%$ of the gross domestic product (GDP). Manufactured goods contribute $86 \%$ of total export, and agricultural goods $14 \%$. Despite that small fraction, the agricultural sector remains a great stimulation to the Thai economy and contributes to the convergence in levels of wealth. World Trade Organization (WTO) is a body designed to stimulate free trade through organizing trade regulations. Free Trade Agreements (FTAs)/Regional Trade Agreements (RTAs) have been massively negotiated. Several FTAs among trading partners have entered into force since the late 1990s. Because of these, the average tariffs on industrial commodities have decreased from $40 \%$ to $4 \%$ from Uruguay to Doha: Agricultural Trade Negotiations (WTO, 2003). Also, the average tariffs seem to lack uniformity with a specific duty adopted for each commodity group. The WTO reports that tariffs on agricultural products range from 0 to $171 \%$ (WTO, 2019). The main purpose of FTAs/RTAs is explicit: amplifying bi-lateral trade and multi-lateral trade by eliminating economic or institutional barriers and eliminating fortress effects. Indeed, FTAs/RTAs appear to essentially affect export performance (Santosa, 2018; Jana, et al., 2020; Harada and Nishitateno, 2021; Kuroiwa, 2021). The obliteration of imported duties on several commodities leads to price reductions across the FTA partners.

Thailand purposely advocates negotiating with several trading partners both bilateral and multilateral FTAs. Recently, Thailand has negotiated FTAs on the bi-lateral level with eight nations, namely the United States of America, China, Japan, Australia, New Zealand, India, Peru, and Bahrain. In this study, we focus on the main agricultural commodities rubber, cassava, fruits and herbs, traded with the five nations China, Japan, Australia, New Zealand, and India. By the end of 2003, the Thai government had signed FTAs with China and India. By mid-2004 there were deals with Japan, Australia, and New Zealand. Recently, there is no consensus regarding the consequences of growth effects in trade openness. This evokes advantages dependent on certain complementary domestic transforms in terms of deregulation of commerce, financial development, and rule of law, etc. Otherwise, international trade constrains long-term growth (Breund and Bolaky, 2008; Chang, Kaltani and Loayza, 2009; Hur and Park, 2012).

Conventional global trade studies principally describe bilateral trade flows between two countries using a gravity model initially introduced by Tinbergen (1962). The basic concept of the gravity model involves Newton's Law of Gravitation. The volume of bilateral trade is derived from a proportion of physical masses, which are represented by gross domestic product (GDP), with geographical distance 
measured by transaction costs for a pair of countries. However, this model possibly supports an argument of approximating the trade potential through Ordinary Least Squares regression, which would describe the central values of the data set. Conceptually, the potential trade indicates the maximum feasible trade to achieve between any two countries that have liberalized their mutual trade restrictions. Instead, the Copula-based Gravity Stochastic Frontier model (GSFM) can manipulate technical efficiency coincident to the upper bound imposed on trade data. Furthermore, the GSFM comes up with two error components; a non-negative error $(\mu)$, indicating the trade inefficiency, and asymmetric noise $(v)$, indicating countryspecific circumstances. The Copula-based Gravity SFM overcomes the strong assumption of independence between these two errors through a large variety of joint distributions accompanied by marginal distributions and copula functions. Accordingly, this approach can be used to examine international trade efficiency under Free Trade Agreement Preferences for Thai agricultural exports.

Every country seeks to achieve its full trade potential through engagement in international trade. Understanding the efficiency levels of Thailand's exports with its major FTA trading partners and the rules of origin on export can help policymakers to manipulate the existing restrictive measures on trade growth. In this paper, the GSFM is augmented with several copulas including Gaussian, Student-t, and Farlie-GumbelMorgenstern copulas, to explore the dependence structure of error components. Furthermore, a panel data framework is adopted to evaluate the trade efficiencies. The rest of the paper is organized as follows: Section II highlights the background incidence of FTAs and Section III details methodology. Section IV presents the dataset and empirical results. Section V concludes and provides policy inferences.

\section{Literature Review}

In 1990, several bilateral FTAs have risen dramatically. The trade promotions from the FTAs occur after many countries entered into such agreements. Many studies regarding the degree of openness and the correlation between an individual country's growth have been examined. The impacts of FTAs can be investigated by considering whether both countries will be better off or worse off when they remove their trade barriers. The evidence of a positive effect of free trade on economic growth had been supported by Dollar (1992), Sachs et al. (1995), Edwards (1998), Frankel and Romer (1999), Dollar and Kraay (2004), Romyen, et al. (2019) by using varies of openness measurements. Moreover, the insignificant or negative impact o

f free trade on economic growth had been reported by Harrison (1996), Rodriguez and Rodrik (2000), Rodrik et al. (2004), Wacziarg and Welch, (2008). 
However, Freund and Bolaky (2008) found that the growth impact of trade openness is importantly positive only when accurate complementary domestic amends are undertaken which include rule of law, better education, deregulations of business, labor market flexibility, even financial developments, etc. Contrarily, the trade would not relate to long-run growth in such an economic system. Additionally, Hur and Park (2012) pointed that FTAs may insignificantly impact total growth in one to ten periods after launch while detecting a significant upward in the gap of GDP per capita and growth rates for a bilateral FTA. Tai Hsieh, et al. (2020) postulated that it is possible to occur negative new gains from liberalization since several domestic disadvantages and productivity are opposed by import productivity losses. Free trade may cause subordinate selection impacts across domestic producers and foreign exporters. Ultimately, this leads to disadvantages to any within-firm productivity effects. Thus, the uneven FTA impacts across nations had been implied within an FTA

\section{Research Methods and Materials}

\subsection{The Gravity Model}

Tinbergen (1962) initially applied Newton's universal law of gravitation to explain patterns of bilateral trade flows between two countries $\mathrm{i}$ and $\mathrm{j}$ as proportional to the economic sizes (generally represented by the gross domestic product: GDP) and inversely proportional to the geographic distance between them. The so-called gravity equation of bilateral trade flow is expressed by:

$$
\operatorname{Trade}_{i j} \propto \frac{\left(G D P_{i}\right)^{\alpha}\left(G D P_{j}\right)^{\beta}}{\left(\text { Dist }_{i j}\right)^{\delta}}
$$

The role of economic sizes $(\alpha, \beta \approx 1)$ is positively related to trade flows, while the role of distance

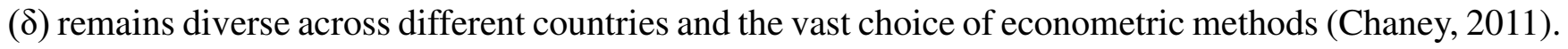
Taking the logarithm to linearize the gravity model provides the elasticity with the following form:

$$
\operatorname{lnTrade}_{i j}=\theta+\alpha \operatorname{lnGDP_{i}}+\beta \ln G D P_{j}-\delta \ln D i s t_{i j}+\varepsilon_{i j},
$$

where Trade $_{i j}$ informs about the bilateral trade between country $i$ and $j, G D P_{i}$ and $G D P_{j}$ stand for the national outputs by countries $i$ and $j$, Dist $t_{i j}$ measures the distance between the two nations, $\theta$ is a constant from taking a $\log$ of a conversion factor, and $\alpha, \beta$, and $\delta$ are the estimated parameters.

\subsection{The Stochastic Frontier Model}

The standard form of the stochastic frontier model (SFM) is defined as

$$
Y_{i}=f\left(X_{i k}^{\prime} \beta\right) . T E_{i}, i=1, \ldots, N
$$




$$
\text { or } \begin{aligned}
\ln Y_{i} & =X_{i k}^{\prime} \beta+\varepsilon_{i}, \\
\varepsilon_{i} & =V_{i}-U_{i}
\end{aligned}
$$

where $Y_{i}$ is the output, $X_{i k}^{\prime} \beta$ represents an $N^{*} K$ matrix with various $K$ inputs, and $\beta$ denotes an $N^{*} K$ matrix of estimated parameters. The function $f(\cdot)$ refers to the stochastic frontier form associated with the Cobb-Douglas production function. The TE indicates technical efficiency and the $\varepsilon_{i}$ is error component comprising noise $V_{i}$ as well as inefficiency $U_{i}$. Principally, the $V_{i}$ is assumed to be normally distributed. The $U_{i}$ are nonnegative half-normal aspects assumed continuous and independent with several inputs.

\subsection{The Gravity with SFM}

The bilateral trade potentials and efficiency levels can be determined by the Gravity with SFM. Particularly, the trade inefficiency from (2.3) can be decomposed into the $V_{i}$ with the two-sided random term and the $U_{i}$ with the one-sided random term, indicating trade inefficiency. To inspect principal determinants of the trade treaties between Thailand and its trading partners, the augmented Gravity with SFM is as follows:

$$
\begin{aligned}
& \operatorname{lnTrade}_{i j}=\beta_{0}+\beta_{1} \operatorname{lnGDP_{i}}+\beta_{2} \operatorname{lnGDP_{j}}+\beta_{3} \ln P o p_{i}+\beta_{4} \ln P o p_{j}+\beta_{5} \ln E x_{i} \\
& +\beta_{6} \operatorname{lnEx_{j}}-\beta_{7} \operatorname{lnDist} t_{i j}-\mu_{i j}+v_{i j} \text {. }
\end{aligned}
$$

Fundamentally, the $\mu_{i j}$ and $v_{i j}$ are supposed to be identical and independent. The $\mu_{i j}$ indicates the failure levels compared to the frontier. Nevertheless, a country having a low technical efficiency will have certain trades below optimal.

\subsection{A Panel Data Copula-based Stochastic Frontier Model with Correlated Noise and Inefficiency}

The panel data methodology provides explicit economic advantages. This can deal with the relationships among variables across time and can track unobservable incidents between trading partner pairs. Moreover, the panel data approach can manipulate the multi-collinearity among the explanatory variables in the model (Baltagi, 1995). For a panel data copula-based stochastic frontier model, the dependence structures are reckoned through marginal probability densities associated with the copula function. Then, we receive the joint probability distribution of inefficiency and noise. A panel data stochastic gravity frontier model has the general form:

$$
y_{i j, t}=f_{\beta}\left(x_{i j, t}\right) \exp \left(v_{i j, t}-u_{i j, t}\right), \varepsilon_{i j, t}=v_{i j, t}-\mu_{i j, t}
$$


where $y_{i j, t}$ denote the volume of bilateral trade between country $i$ and country $j$ at a certain time $t$ and $i=1, \ldots, n, j=1, \ldots, n, t=1, \ldots, T . f_{\beta}(\cdot)$ refers to the deterministic trade frontier respecting the error efficiency, and $x_{i j, t}$ informs on relevant bilateral trade factors. Regarding the error components, $v_{i j}$ is the statistical noise and $u_{i j}$ is the inefficiency. The deterministic frontier subject to noise $f_{\beta}^{S}\left(x_{i j, t}\right) \equiv$ $f_{\beta}\left(x_{i j, t}\right) \exp$ is called the stochastic frontier. The distributions of $v_{i j, t}$ and $u_{i j, t} \operatorname{are} v_{i j, t} \sim N\left(0, \sigma_{v}^{2}\right),-\infty<$ $v_{i j, t}<\infty$ and $\mu_{i j, t} \sim N^{+}\left(0, \sigma_{\mu}^{2}\right), 0<u_{i j, t}<\infty$. This provides the maximum capacity output from a certain input bundle $x_{i j, t}$ without random residual judgment. Theoretically, finite production $y_{i j, t}$ is ordinarily underneath its potential production in such a way that $y_{i j, t} \leq f_{\beta}^{S}\left(x_{i j, t}\right) \forall_{i j, t}$. The deficiency of the real output concerning the potential production is assessed by

$$
\begin{gathered}
e^{-\mu_{i j, t}}=\frac{y_{i j, t}}{f_{\beta}^{S}\left(x_{i j, t}\right)} \\
0 \leq \frac{y_{i j, t}}{f_{\beta}^{S}\left(x_{i j, t}\right)} \leq 1
\end{gathered}
$$

Since $u_{i j, t}$ is non-negative, the parameters of the probability distribution of $u_{i j, t}$ are then taken into account regarding the inference of the stochastic frontier analysis. Given $F_{\pi i t}\left(v_{i j, t}\right), G_{\eta i t}\left(\mu_{i j, t}\right)$ as the distribution functions and $f_{\pi i j, t}\left(v_{i j, t}\right), g_{\eta i j, t}\left(\mu_{i j, t}\right)$ as the probability density functions of noise and inefficiency, accompanied by the countries $i$ and $j$ at time $t$, let $\pi_{i j, t}$ and $\eta_{i j, t}$ denote the parameter vectors of $v_{i j}$ and $\mu_{i j}$. Also, let $\mu_{i j}=\left(\mu_{i j, 1}, \ldots, \mu_{i j, T}\right)^{\prime}, v_{i j}=\left(v_{i j, 1}, \ldots, v_{i j, T}\right)^{\prime}, \eta_{i j}=\left(\eta_{i j, 1}, \ldots, \eta_{i j, T}\right)^{\prime}$ and $\pi_{i j}=$ $\left(\pi_{i j, 1}, \ldots, \pi_{i j, T}\right)^{\prime}$. We assume that a $2 T$-variate copula can properly estimate the dependency of $\mu_{i j, t}$ and $v_{i j, t}$. The joint probability density function of $\left(\mu_{i j, t}\right.$ and $\left.v_{i j, t}\right)$ is expressed by:

$$
\left.f_{\gamma_{i j}}\left(\mu_{i j, t}, v_{i j, t}\right)\right)=\left(\prod_{t=1}^{T} g_{\eta i j, t}\left(\mu_{i j, t}\right) f_{\pi i j, t}\left(v_{i j, t}\right)\right) c_{\alpha_{i j}}\left(G\left(\mu_{i j, 1}\right), \ldots, G\left(\mu_{i j, T}\right), F\left(v_{i j, 1}\right), \ldots F\left(v_{i j, T}\right)\right)
$$

where $\gamma_{i j}=\left(\pi_{i j}, \eta_{i j}, \alpha_{i j}\right)$, and $\alpha_{i j}$ denotes the vector of copula parameters. It can be assumed that the temporal dependencies among residual and inefficiency procure the joint density function and the dependence structure at a certain unit $i j$.

\subsection{Correlated Noise and Inefficiency Modeling using Normal and T Copula}

According to the noise-inefficiency dependence and temporal dependence of the inefficiency assumption, the temporal dependence among residuals principally disappears for each trading partner country along with three assumptions. Firstly, the stochastic dependences of the noise and the inefficiency 
accompanied by any trading partner country are identical across times such as $\operatorname{Corr}\left(\mu_{i j, t}, v_{i j, t}\right)=$ $\rho, \forall i j$ and $t$. There is no time dependence of order one or more between the noise and inefficiency so $\operatorname{Corr}\left(\mu_{i j, t}, v_{i j, t-s}\right)=\operatorname{Corr}\left(v_{i j, t}, \mu_{i j, t-s}\right)=0, \forall s=1, \ldots, T$. Secondly, the time dependence of inefficiency is order one and identical for the ijth trading partner nations at any two coherent periods so that $\operatorname{Corr}\left(\mu_{i j, t}, \mu_{i j, t-1}\right)=\psi$ and there is no time dependence of order two or more among inefficiencies so that $\operatorname{Corr}\left(\mu_{i j, t}, \mu_{i j, t-s}\right)=0, \forall s=2, \ldots, T$. Finally, the time dependence of order one or more among the noise does not exist so that $\operatorname{Corr}\left(v_{i j, t}, v_{i j, t-s}\right)=0, \forall s=2, \ldots, T$ (Das, 2015). Consequently, the joint density function of $\mu_{i j, t}$ and $v_{i j, t}$ respecting to the normal copula is expressed by

$$
\begin{gathered}
\left.f_{\gamma_{i j}}\left(\mu_{i j, t}, v_{i j, t}\right)\right)=\left(\prod_{t=1}^{T} \frac{1}{\sigma_{v}} \phi\left(\frac{v_{i j, t}}{\sigma_{v}}\right) \frac{1}{\sigma_{\mu}} \phi\left(\frac{\mu_{i j, t}}{\sigma_{\mu}}\right)\right) \frac{1}{|R|^{\frac{1}{2}}} \exp \left[-\frac{1}{2} \varsigma^{\prime}\left(R^{-1}-I\right) \varsigma\right], \\
\text { where } \varsigma=\left(\Phi^{-1}(2 \Phi)\left(\frac{\mu_{i j, 1}}{\sigma_{\mu}}\right)-1\right), \ldots, \Phi^{-1}\left(2 \Phi\left(\frac{\mu_{i j, T}}{\sigma_{\mu}}\right)-1\right), \\
\left.\left.\Phi^{-1}\left(\Phi\left(\frac{v_{i j, 1}}{\sigma_{v}}\right)\right), \ldots, \Phi^{-1}\left(\Phi\left(\frac{v_{i j, T}}{\sigma_{v}}\right)\right)\right),\right)^{\prime} \\
R=\left(\begin{array}{ccc}
R_{11} & R_{12} \\
R_{21} & R_{22}
\end{array}\right), \\
R_{11}=\left(\begin{array}{ccccc}
1 & \psi & 0 & \cdots & 0 \\
\psi & 1 & \psi & \cdots & 0 \\
\cdots & \cdots & \cdots & \cdots & \cdots \\
0 & 0 & 0 & \cdots & 1
\end{array}\right), \\
R_{12}=R_{21}=\left(\begin{array}{ccccc}
\rho & 0 & \cdots & 0 \\
0 & \rho & \cdots & 0 \\
\cdots & \cdots & \cdots & \cdots \\
0 & 0 & 0 & \rho
\end{array}\right) \text { and } R_{22}=\left(\begin{array}{cccc}
1 & 0 & \cdots & 0 \\
0 & \rho & \cdots & 0 \\
\cdots & 0 & 0 & \cdots \\
0 & 0 & 0 & \rho
\end{array}\right) .
\end{gathered}
$$

where $\rho$ denotes a copula parameter associated with joint dependence between noise and inefficiency independence. $\psi$ refers to a copula parameter associated with lagged dependence within inefficiency. Rewriting $v_{i j, t}=\varepsilon_{i j, t}+\mu_{i j, t}$ in Equation (3.6) and integrating over $\mu_{i j}, t$, the density function of $\varepsilon_{i j}$ is expressed by:

$$
h\left(\varepsilon_{i j}\right)=\int_{0}^{\infty} \cdots \int_{0}^{\infty}\left(\prod_{t} f\left(\varepsilon_{i j, t}+\mu_{i j, t}\right)\right) C_{\alpha_{i j}, t}\left(\prod_{t} g\left(\mu_{i j, t}\right)\right) d \mu_{i j, t}
$$

where

$$
C_{\alpha_{i j}}=C_{\alpha_{i j}}\left(G\left(\mu_{i j 1}\right), \ldots, G\left(\mu_{i j T}\right), F\left(\varepsilon_{i j 1}+\mu_{i j 1}\right), \ldots F\left(\varepsilon_{i j T}+\mu_{i j T}\right)\right) .
$$

For the tail dependence property, the multivariate $\mathrm{T}$ copula can deal with this dependence on Thai export volumes. Given that $\rho$ is asymmetric, positive definite with diagonal $\rho$ and $T_{\rho, v}$, the standardized 
Student's distribution with $v$ degrees of freedom and correlation matrix $\rho$, the joint density function of $\mu_{i j}, v_{i j}$ under T copula is calculated as follows:

$$
f_{\gamma}\left(\mu_{i j, t}, v_{i j, t}\right)=|\rho|^{-\frac{1}{2}} \frac{\Gamma\left[\frac{v_{i j, t}+T}{2}\right]\left[\Gamma\left(\frac{v_{i j, t}}{2}\right)\right]^{T}\left[1+\frac{1}{v_{i j, t}} \xi^{T} \rho^{-1} \xi\right]^{\frac{-v_{i j, t}+T}{2}}}{\left[\Gamma\left[\frac{v_{i j, t}+T}{2}\right]\right]^{T}\left[\Gamma\left(\frac{v_{i j, t}}{2}\right)\right] \prod_{t=1}^{T}\left[1+\frac{\xi_{T}^{2}}{v_{i j, t}}\right]^{\frac{-v_{i j, t}+T}{2}}},
$$

where $\xi_{n}=t_{v}^{-1}\left(\mu_{n}\right), t_{v}^{-1}$ is the inverse of the univariate Student's distribution.

According to the Jondrow et al. (1982) estimator of technical inefficiency, the SFM accompanied by the correlated error element through copula criteria can be written as:

$$
\begin{aligned}
& T I E_{i}=E\left[\mu_{i j} \mid \varepsilon_{i j}\right]=\frac{1}{h\left(\varepsilon_{i j}\right)} \int_{0}^{\infty} \mu_{i j} f_{\gamma}\left(\mu_{i j}, \varepsilon_{i j}\right) d \mu_{i j} \\
& =\frac{1}{h\left(\varepsilon_{i j}\right)} \int_{0}^{\infty} \mu_{i j}\left(\prod_{t} f\left(\varepsilon_{i j}+\mu_{i j}\right)\right) C_{\alpha_{i j}}\left(\prod_{t} g\left(\mu_{i j}\right)\right) d \mu_{i j} .
\end{aligned}
$$

\section{Empirical Results}

\subsection{Dataset}

The panel data consisting of the four bilateral trading partners with Thailand for the agricultural commodities rubber, cassava, fruits, and herbs were taken from Information Technology and Communication Center, Ministry of Commerce. One of the advantages of utilizing the panel data is that it can deal with the behavior of technical inefficiency across time. The data on the gross domestic product $(G D P)$, which is a proxy for the size of the economy, population $(P O P)$ the exchange rate $(E X)$ were collected from the World Development Indicators (WDI) over the period from 1998 to 2019. The distance data are received from the CEPII Geodist dyadic dataset. Then, the variables were transformed into logarithms. Figure 1 shows the five agricultural commodity volumes (million US\$) of Thailand with the FTA trading partners China, Japan, New Zealand, Australia, and India. In this study, the products rubber, cassava, fruits, and herbs are utilized as proxies representing the agricultural commodities, since they regularly make up a large share of export to these destinations. The FTAs have generally been established since 2003 for each trading partner. Afterward, the volumes of agricultural commodities have greatly expanded but possibly fluctuate over time. 


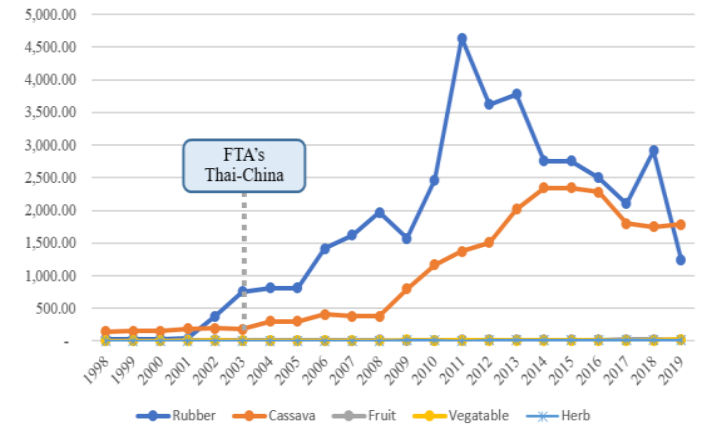

1(a) China

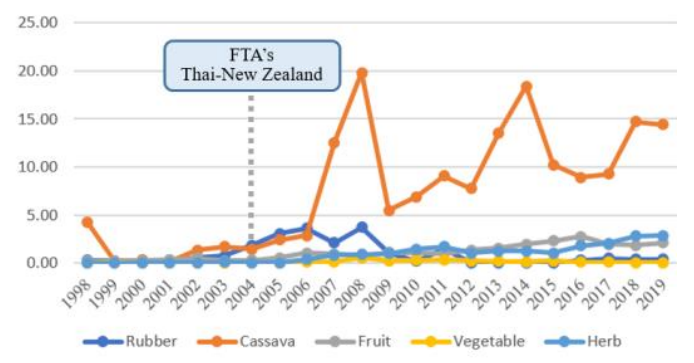

1(c) New Zealand

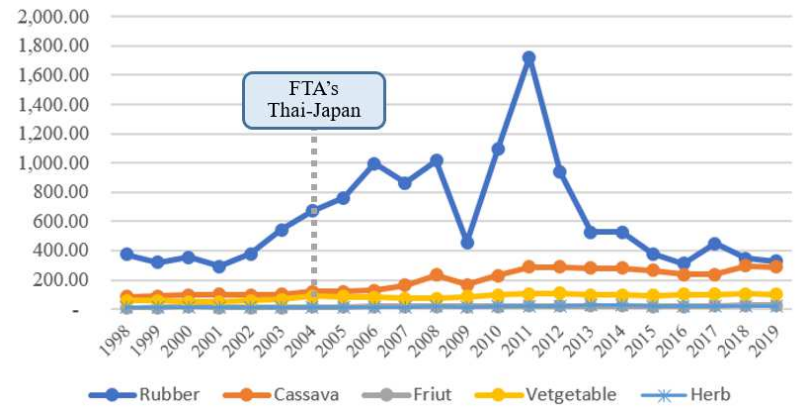

1(b) Japan

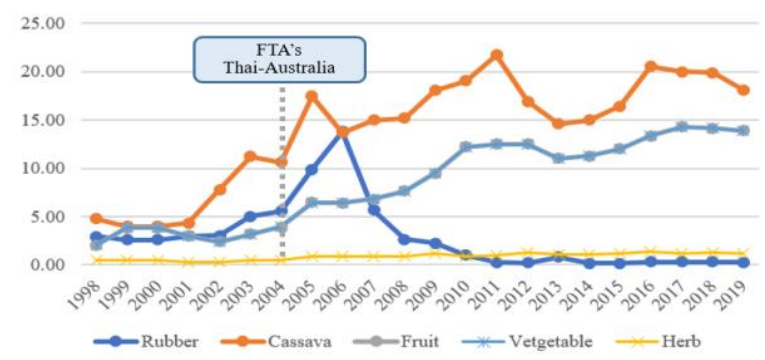

1(d) Australia

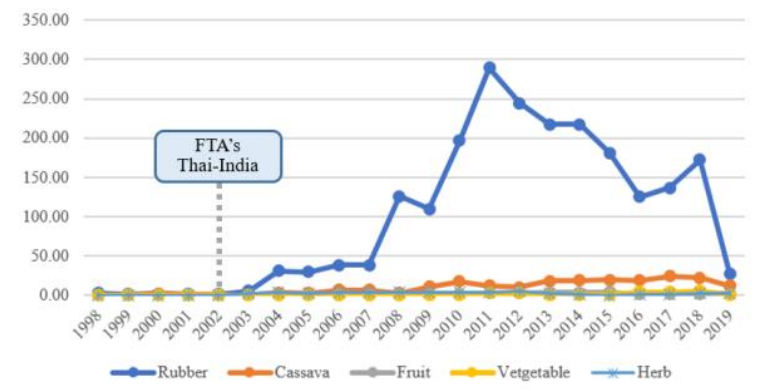

1(e) India

Figure 1: The volumes of five agricultural commodities exported to Thailand's FTA trading partners

\subsection{Empirical Findings}

To emphasize the incidences of the noise-inefficiency dependence and temporal dependence amongst the model's error components, we augment the standard frontier model associated with the gravity model using the copula criteria. The standard gravity-SFM is assumed to have independent error components. Moreover, the Gaussian copula, the Student-t, and the multivariate multiparameter FarlieGumbel-Morgenstern (FGM) copulas-based Gravity SFMs were constructed to measure the trade technical efficiency. For model selection, we determine Akaike's information criterion (AIC) and Bayes 
information criterion (BIC) to compare the candidate models. Table 1 summarizes the estimated results for standard Gravity-SFM and copulas-based Gravity-SFMs.

The results indicate that the Student t copula-based SFM in every part of agriculture commodity offers minimized both AIC and BIC for rubber (AIC = 796.600 and BIC = 852.198), cassava (AIC = 633.073 and $\mathrm{BIC}=688.671)$, fruits $(\mathrm{AIC}=677.982$ and $\mathrm{BIC}=733.580)$, vegetables $(\mathrm{AIC}=676.152$ and $\mathrm{BIC}=749.725)$ and herbs $(\mathrm{AIC}=648.123$ and $\mathrm{BIC}=760.190)$. Accordingly, the Student $\mathrm{t}$ copula-based SFMs are utilized to estimate technical efficiency. Empirically, the Thai GDP, partner GDP, partner's population, and exchange rates are positively significant at the $1 \%$ level of significance in promoting Thai exports. For instance, a $1 \%$ growth in Thai and partner GDPs are associated with increases in Thai rubber export by $1.039 \%$ and $1.898 \%$, respectively. A $1 \%$ growth in the partner's population stimulates rubber export by $0.817 \%$, etc. It is verified that bilateral trade expands when the GDPs of both trading partners rise, which is consistent with the studies of Anderson (2014) and Boonyakunakorn, et al. (2018).

Table 1: The estimated results of standard Gravity-SFM and copulas-based Gravity-SFMs

\begin{tabular}{|c|c|c|c|c|c|c|c|c|}
\hline \multirow[t]{2}{*}{ Variable } & \multicolumn{2}{|c|}{ Gravity-SFM } & \multicolumn{2}{|c|}{$\begin{array}{c}\text { Gaussian copula- } \\
\text { based SFM }\end{array}$} & \multicolumn{2}{|c|}{$\begin{array}{c}\text { Student t copula-based } \\
\text { SFM }\end{array}$} & \multicolumn{2}{|c|}{$\begin{array}{c}\text { FGM copula-based } \\
\text { SFM }\end{array}$} \\
\hline & Coefficient & S.E. & Coefficient & S.E. & Coefficient & S.E. & Coefficient & S.E. \\
\hline \multicolumn{9}{|l|}{ - Rubber } \\
\hline Constant & -0.694 & 0.096 & 0.173 & 1.246 & 0.458 & 0.851 & 0.619 & 0.520 \\
\hline $\ln G D P_{i}$ & $0.107^{* * *}$ & 0.027 & $1.122^{* * * *}$ & 0.017 & $1.039^{* * *}$ & 0.003 & $0.806^{* * *}$ & 0.099 \\
\hline $\ln G D P_{j}$ & $1.829^{* * *}$ & 0.071 & $0.870^{* * *}$ & 0.045 & $1.898^{* * *}$ & 0.015 & $0.654^{* * *}$ & 0.042 \\
\hline $\ln P O P_{i}$ & -1.802 & 0.050 & -0.438 & 0.034 & -2.075 & 0.035 & -3.265 & 0.135 \\
\hline $\ln P O P_{j}$ & $0.674^{* *}$ & 0.063 & $1.667^{* *}$ & 0.045 & $0.817^{*}$ & 0.081 & $9.953^{*}$ & 0.246 \\
\hline lnDistij & -8.220 & 0.215 & -3.029 & 0.129 & -9.654 & 0.168 & -13.639 & 0.164 \\
\hline $\ln E X_{i}$ & $0.381^{* *}$ & 0.015 & $0.153^{* *}$ & 0.008 & $0.464^{* * *}$ & 0.036 & 0.620 & 0.058 \\
\hline $\ln E X_{j}$ & -2.555 & 0.011 & -1.330 & 0.034 & -3.637 & 0.058 & -2.897 & 0.440 \\
\hline$\sigma_{\mu}$ & $0.471^{* * *}$ & 0.336 & $0.056^{* * *}$ & 0.013 & $0.878^{*}$ & 0.223 & $0.371^{* *}$ & 0.234 \\
\hline$\sigma_{v}$ & $0.299^{*}$ & 0.065 & $0.836^{* *}$ & 0.011 & $0.199^{* *}$ & 0.046 & $0.169^{*}$ & 0.294 \\
\hline$\rho_{1}$ & & & -0.319 & 0.098 & $0.934^{* * *}$ & 0.053 & -0.990 & 0.177 \\
\hline$\rho_{2}$ & & & $0.252^{* *}$ & 0.051 & $0.990^{* * *}$ & 0.001 & -0.053 & 0.268 \\
\hline$\rho_{3}$ & & & - & - & $0.720^{* *}$ & 0.029 & - & - \\
\hline$\rho_{4}$ & & & - & - & $0.410^{*}$ & 0.064 & - & - \\
\hline AIC & \multicolumn{2}{|l|}{1526.374} & \multicolumn{2}{|c|}{1466.382} & \multicolumn{2}{|c|}{796.600} & \multicolumn{2}{|c|}{1386.497} \\
\hline BIC & \multicolumn{2}{|l|}{1627.396} & \multicolumn{2}{|c|}{1514.035} & \multicolumn{2}{|c|}{852.198} & \multicolumn{2}{|c|}{1434.152} \\
\hline - Cassava & & & & & & & & \\
\hline Constant & 0.59 & 0.192 & $0.101^{* * *}$ & 0.651 & $0.615^{* *}$ & 0.139 & 0.627 & 2.886 \\
\hline
\end{tabular}




\begin{tabular}{|c|c|c|c|c|c|c|c|c|}
\hline \multirow[t]{2}{*}{ Variable } & \multicolumn{2}{|c|}{ Gravity-SFM } & \multicolumn{2}{|c|}{$\begin{array}{c}\text { Gaussian copula- } \\
\text { based SFM }\end{array}$} & \multicolumn{2}{|c|}{$\begin{array}{c}\text { Student t copula-based } \\
\text { SFM }\end{array}$} & \multicolumn{2}{|c|}{$\begin{array}{c}\text { FGM copula-based } \\
\text { SFM }\end{array}$} \\
\hline & Coefficient & S.E. & Coefficient & S.E. & Coefficient & S.E. & Coefficient & S.E. \\
\hline $\ln G D P_{i}$ & $1.23^{* * *}$ & 0.063 & $1.752^{* * * *}$ & 0.001 & $1.188^{* * *}$ & 0.051 & 1.232 & 0.054 \\
\hline $\ln G D P_{j}$ & 0.03 & 1.882 & $0.483^{* * *}$ & 0.054 & $0.062^{* *}$ & 0.029 & -0.459 & 1.953 \\
\hline $\ln P O P_{i}$ & $-3.32^{* * * *}$ & 0.155 & $0.415^{*}$ & 0.010 & $3.172^{* *}$ & 0.006 & -3.069 & 0.141 \\
\hline $\ln P O P_{j}$ & 8.73 & 0.184 & $0.404^{* * *}$ & 0.022 & 0.244 & 0.072 & 9.137 & 0.055 \\
\hline lnDist ${ }_{i j}$ & $-12.92^{* * *}$ & 0.627 & $-0.945^{*}$ & 0.024 & -12.477 & 0.030 & -12.117 & 0.553 \\
\hline $\ln E X_{i}$ & 0.02 & 0.043 & $-0.784^{* * *}$ & 0.007 & $0.023^{* *}$ & 0.027 & $0.031^{* * *}$ & 0.036 \\
\hline $\ln E X_{j}$ & $-2.36^{* * *}$ & 0.845 & $-0.109^{* * *}$ & 0.112 & -1.782 & 0.041 & -2.367 & 0.655 \\
\hline$\sigma_{\mu}$ & $0.456^{* *}$ & 0.195 & $0.035^{* * *}$ & 0.005 & $0.647^{* *}$ & 0.033 & 0.489 & 0.041 \\
\hline$\sigma_{v}$ & $0.691^{* * * *}$ & 0.013 & $0.324^{* * * *}$ & 0.016 & $0.541^{*}$ & 0.077 & 0.324 & 0.163 \\
\hline$\rho_{1}$ & & & $0.568^{* * *}$ & 0.084 & $0.653^{* * *}$ & 0.049 & 0.990 & 0.492 \\
\hline$\rho_{2}$ & & & $-0.104^{* * *}$ & 0.068 & $0.790^{* * *}$ & 0.001 & -0.084 & 0.268 \\
\hline$\rho_{3}$ & & & - & - & $0.471^{*}$ & 0.015 & - & - \\
\hline$\rho_{4}$ & & & - & - & $0.054^{*}$ & 0.043 & - & - \\
\hline AIC & \multicolumn{2}{|c|}{1425.386} & \multicolumn{2}{|c|}{1392.558} & \multicolumn{2}{|c|}{633.073} & \multicolumn{2}{|c|}{1247.293} \\
\hline BIC & \multicolumn{2}{|c|}{1528.394} & \multicolumn{2}{|c|}{1440.216} & \multicolumn{2}{|c|}{688.671} & \multicolumn{2}{|c|}{1294.948} \\
\hline - Fruit & & & & & & & 0.130 & \\
\hline Constant & 0.971 & 0.099 & $0.161^{* * *}$ & 0.791 & $0.106^{*}$ & 0.171 & & 0.687 \\
\hline $\ln G D P_{i}$ & 1.371 & 0.088 & $1.493^{* * *}$ & 0.074 & $1.325^{* * *}$ & 0.064 & 0.730 & 0.100 \\
\hline $\ln G D P_{j}$ & -6.968 & 0.042 & $1.191^{* * *}$ & 0.141 & $0.920^{* *}$ & 0.026 & -0.649 & 3.605 \\
\hline $\ln P O P_{i}$ & -1.129 & 0.017 & -1.127 & 0.204 & -0.579 & 0.150 & -0.245 & 0.262 \\
\hline $\ln P O P_{j}$ & 5.837 & 0.062 & $1.737^{* *}$ & 0.200 & $0.5412^{*}$ & 0.091 & 0.449 & 0.120 \\
\hline lnDist $_{i j}$ & -3.631 & 0.074 & -3.032 & 0.818 & $-1.120^{*}$ & 0.074 & -0.458 & 1.020 \\
\hline $\ln E X_{i}$ & -2.611 & 0.053 & $-0.249^{* *}$ & 0.052 & $-0.218^{* * *}$ & 0.030 & -0.042 & 0.068 \\
\hline $\ln E X_{j}$ & 1.207 & 0.071 & $0.010^{* * *}$ & 0.095 & -0.413 & 0.035 & 0.292 & 1.206 \\
\hline$\sigma_{\mu}$ & 0.598 & 0.018 & $0.472^{* * *}$ & 0.070 & $0.627^{* *}$ & 0.056 & 0.896 & 0.077 \\
\hline$\sigma_{v}$ & 0.364 & 0.845 & $0.147^{*}$ & 0.104 & $0.644^{*}$ & 0.011 & 0.572 & 0.259 \\
\hline$\rho_{1}$ & & & $0.833^{* *}$ & 0.154 & $0.790^{* * *}$ & 0.048 & 0.990 & 0.596 \\
\hline$\rho_{2}$ & & & $-0.096^{*}$ & 0.268 & $0.490^{* * *}$ & 0.001 & -0.089 & 0.268 \\
\hline$\rho_{3}$ & & & - & - & $0.500^{* * *}$ & 0.020 & - & - \\
\hline$\rho_{4}$ & & & - & - & 0.620 & 0.043 & - & - \\
\hline AIC & \multicolumn{2}{|c|}{1437.306} & \multirow{2}{*}{\multicolumn{2}{|c|}{$\begin{array}{l}1338.892 \\
1386.557\end{array}$}} & \multirow{2}{*}{\multicolumn{2}{|c|}{$\begin{array}{l}677.982 \\
733.580\end{array}$}} & \multirow{2}{*}{\multicolumn{2}{|c|}{$\begin{array}{l}1380.869 \\
1428.524\end{array}$}} \\
\hline BIC & & & & & & & & \\
\hline \multicolumn{9}{|l|}{ - Vegetable } \\
\hline Constant & -3.940 & 1.156 & $0.206^{* * *}$ & 1.285 & 0.210 & 1.055 & $0.313^{* *}$ & 0.2987 \\
\hline $\ln G D P_{i}$ & $2.288^{* * *}$ & 0.083 & $2.295^{* * *}$ & 0.084 & $2.332^{* *}$ & 0.073 & $0.414^{* * *}$ & 0.092 \\
\hline $\ln G D P_{j}$ & -0.719 & 0.158 & $-0.786^{* *}$ & 0.213 & -0.785 & 0.024 & -0.213 & 0.682 \\
\hline $\ln P O P_{i}$ & -1.352 & 0.212 & -1.386 & 0.211 & -1.416 & 0.096 & -1.754 & 0.573 \\
\hline $\ln P O P_{j}$ & $4.502^{* * * *}$ & 0.711 & $2.176^{*}$ & 0.646 & $2.2198^{* * *}$ & 0.022 & $3.701^{*}$ & 0.173 \\
\hline
\end{tabular}




\begin{tabular}{|c|c|c|c|c|c|c|c|c|}
\hline \multirow[t]{2}{*}{ Variable } & \multicolumn{2}{|c|}{ Gravity-SFM } & \multicolumn{2}{|c|}{$\begin{array}{c}\text { Gaussian copula- } \\
\text { based SFM }\end{array}$} & \multicolumn{2}{|c|}{$\begin{array}{c}\text { Student t copula-based } \\
\text { SFM }\end{array}$} & \multicolumn{2}{|c|}{$\begin{array}{c}\text { FGM copula-based } \\
\text { SFM }\end{array}$} \\
\hline & Coefficient & S.E. & Coefficient & S.E. & Coefficient & S.E. & Coefficient & S.E. \\
\hline $\ln { }_{i s t_{i j}}$ & -1.966 & 0.831 & -2.099 & 0.824 & $-2.146^{* * * *}$ & 0.063 & -4.929 & 0.929 \\
\hline $\ln E X_{i}$ & $0.270^{* *}$ & 0.056 & $0.268^{* *}$ & 0.054 & $0.264^{* * *}$ & 0.047 & $0.751^{* *}$ & 0.626 \\
\hline $\ln E X_{j}$ & -2.439 & 1.002 & -2.105 & 0.983 & -2.016 & 0.090 & $1.629^{* * *}$ & 0.110 \\
\hline$\sigma_{\mu}$ & $0.611^{* * *}$ & 0.216 & $0.656^{* * * *}$ & 0.111 & $0.815^{*}$ & 0.078 & 0.768 & 0.522 \\
\hline$\sigma_{v}$ & $0.343^{* *}$ & 0.399 & $0.648^{* * *}$ & 0.246 & $0.404^{* *}$ & 0.033 & $0.008^{* * *}$ & 0.524 \\
\hline$\rho_{1}$ & & & $0.732^{* *}$ & 0.307 & $0.677^{* * * *}$ & 0.068 & 0.594 & 0.280 \\
\hline$\rho_{2}$ & & & $-0.080^{*}$ & 0.268 & $0.990^{*}$ & 0.001 & -0.046 & 0.380 \\
\hline$\rho_{3}$ & & & - & - & $0.063^{* * *}$ & 0.017 & - & - \\
\hline$\rho_{4}$ & & & - & - & $0.137^{* *}$ & 0.035 & - & - \\
\hline AIC & \multicolumn{2}{|c|}{1426.396} & \multicolumn{2}{|c|}{1335.973} & \multicolumn{2}{|c|}{676.152} & \multicolumn{2}{|c|}{1358.847} \\
\hline $\mathrm{BIC}$ & \multicolumn{2}{|c|}{1493.472} & \multicolumn{2}{|c|}{1383.636} & \multicolumn{2}{|c|}{749.725} & \multicolumn{2}{|c|}{1406.502} \\
\hline \multicolumn{9}{|l|}{ - Herb } \\
\hline Constant & -5.853 & 0.091 & $0.2483^{* * *}$ & 5.468 & $0.197^{* *}$ & 4.568 & 0.323 & 0.743 \\
\hline $\ln G D P_{i}$ & $4.532^{* * *}$ & 0.053 & $0.389^{* * *}$ & 0.056 & $0.375^{* *}$ & 0.047 & $0.101^{* *}$ & 0.096 \\
\hline $\ln G D P_{j}$ & -3.046 & 0.415 & $0.867^{* * *}$ & 0.231 & $1.222^{* * *}$ & 0.163 & -1.085 & 0.348 \\
\hline $\ln P O P_{i}$ & -1.008 & 0.191 & -1.399 & 0.142 & -1.169 & 0.114 & -1.251 & 0.244 \\
\hline $\ln P O P_{j}$ & 3.584 & 0.582 & 3.633 & 0.384 & $2.705^{* *}$ & 0.629 & $3.632^{*}$ & 0.243 \\
\hline $\operatorname{lnDist}_{i j}$ & $-3.167^{* * *}$ & 0.764 & $-4.943^{*}$ & 0.564 & $-4.206^{* * *}$ & 0.456 & -4.281 & 0.958 \\
\hline $\ln E X_{i}$ & $5.823^{*}$ & 0.053 & $0.559^{* *}$ & 0.037 & $0.544^{* *}$ & 0.032 & $0.544^{* * *}$ & 0.063 \\
\hline $\ln E X_{j}$ & -3.184 & 0.081 & -1.112 & 0.611 & -0.148 & 0.499 & -0.062 & 0.144 \\
\hline$\sigma_{\mu}$ & $0.295^{* * *}$ & 0.193 & $1.175^{* *}$ & 0.235 & $0.505^{* *}$ & 0.259 & $0.841^{* * *}$ & 0.139 \\
\hline$\sigma_{v}$ & $0.475^{*}$ & 0.222 & $3.182^{*}$ & 0.338 & $1.927^{* *}$ & 0.386 & 0.500 & 0.456 \\
\hline$\rho_{1}$ & & & $0.369^{* * *}$ & 0.012 & $0.087^{* * *}$ & 0.116 & 0.990 & 0.352 \\
\hline$\rho_{2}$ & & & -0.523 & 0.089 & $0.190^{*}$ & 0.001 & -0.092 & 0.268 \\
\hline$\rho_{3}$ & & & - & - & $0.320^{* *}$ & 4.199 & - & - \\
\hline$\rho_{4}$ & & & - & - & $0.020^{* * *}$ & 0.643 & - & - \\
\hline AIC & \multicolumn{2}{|c|}{1472.386} & \multicolumn{2}{|c|}{1367.127} & \multicolumn{2}{|c|}{648.123} & \multicolumn{2}{|c|}{1339.762} \\
\hline BIC & & \multicolumn{2}{|c|}{1414.773} & \multicolumn{2}{|c|}{760.190} & \multicolumn{2}{|c|}{1387.417} \\
\hline
\end{tabular}

Note: Calculation, Significance codes: $*=0.1, * *=0.05, * * *=0.01$.

\subsection{Thailand's Agricultural Export Efficiency}

The technical efficiency (TE) in terms of trade efficiency belonging to an individual country is determined as the ratio of the observed agricultural commodities with the corresponding gravity model properties such as economic mass, geographic distance, and other relevant global trade elements utilized by the trading partners. Hence, Thai export efficiency levels under the FTA schemes are estimated using the copula-based Gravity SFM for each of the trading countries and their frontier specifications. Export 
potential conceptually imposes either a country's trade performance at the optimum frontier with frictionless trade regimes, or it is the maximum level of trade at certain determinants in case of the least restrictions and trade barriers within the global market. If a country virtually merchandises its commodities to the global market at the trading frontier, it can achieve economic efficiency. This status indicates a country reaches its technical and allocative efficiency (Kaliraja and Shand, 1999; Roperto and Edgardo, 2014).

In this study, if Thailand reaches an efficient level of exports to the FTA trading partners, this indicates that Thai export performance approaches its maximum potential with that nation. On the other hand, an inefficient position in exports is suggested by poorer actual data than the plausible trade potential. The Thai FTA partner countries in this study were China (CH), Japan (JP), New Zealand (NZ), Australia (AUS), and India (IND). The higher TE scores of Thai agricultural exports convey that the export performance to a partner country virtually reached its maximum export potential. For China, Thailand can gain considerably from rubber compared to the other commodities, but recently this export has been down for a while, as seen in Figure 2(a). For Japan in Figure 2(b), cassava and vegetables have been exported consistently to Japan, which is one of the main cassava importers from Thailand. With New Zealand shown in Figure 2(c), fruits and vegetables have performed continuously, while herbs have remarkably increased lately. For Australia in Figure 2(d), the trends are similar to New Zealand. For India in Figure 2(e), cassava, fruits and vegetables have performed steadily in trade efficiency, while rubber and herbs appear to be vulnerable.

A summary of TE scores for each agricultural commodity is listed in Table 2. The highest and the lowest TE levels from China are rubber (0.56) and fruits (0.41), from Japan they are cassava (0.77) and rubber (0.34), from New Zealand are vegetables (0.47) and rubber (0.30), from Australia are herbs $(0.54)$ and cassava (0.07), and from India are cassava (0.60) and fruits (0.48).

Table 2: The overall TE of Thai agricultural exports to FTA partner countries

\begin{tabular}{|l|c|c|c|c|c|c|}
\hline \multirow{2}{*}{$\begin{array}{c}\text { Thai-FTAs } \\
\text { partnerships }\end{array}$} & \multicolumn{7}{|c|}{ TE of Thai agricultural exports } \\
\cline { 2 - 7 } & Rubber & Cassava & Fruit & Vegetable & Herb & Overall TE \\
\hline CH & 0.56 & 0.48 & 0.41 & 0.45 & 0.50 & 0.48 \\
\hline JP & 0.34 & 0.77 & 0.41 & 0.48 & 0.42 & 0.48 \\
\hline NZ & 0.30 & 0.39 & 0.42 & 0.47 & 0.54 & 0.39 \\
\hline INDS & 0.11 & 0.07 & 0.44 & 0.48 & 0.33 & 0.39 \\
\hline
\end{tabular}




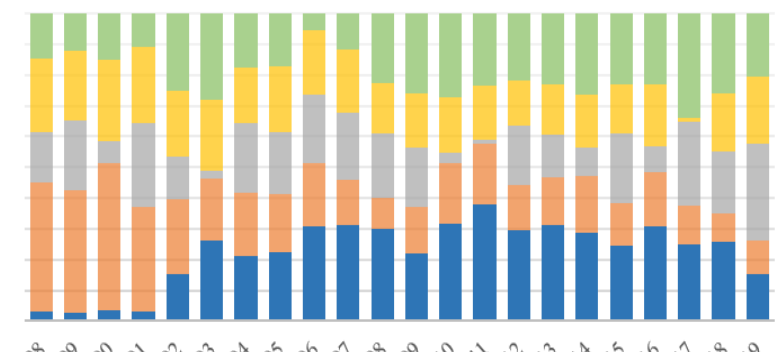

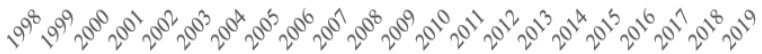

2(a) China

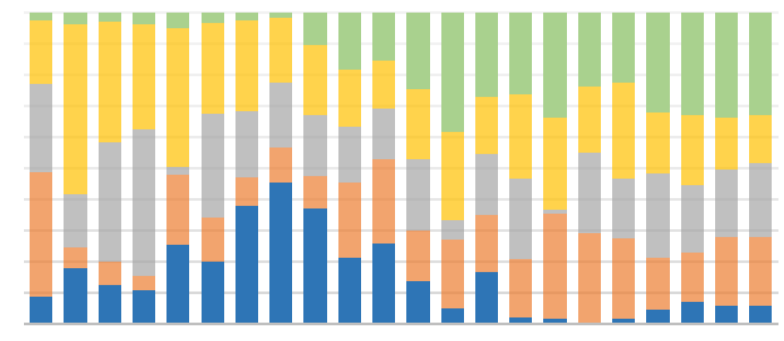

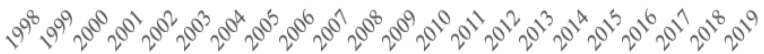

2(c) New Zealand

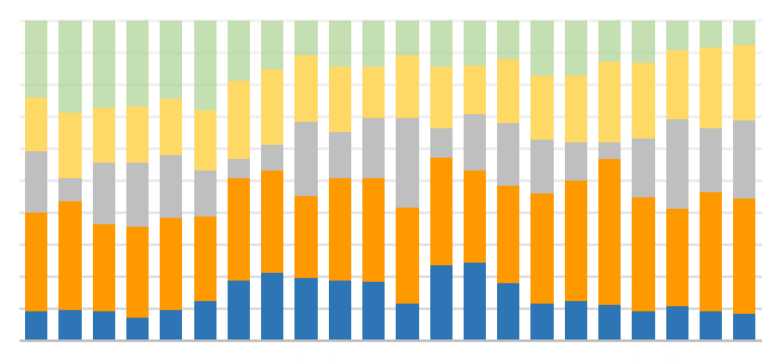

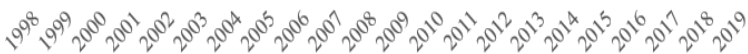

2(b) Japan

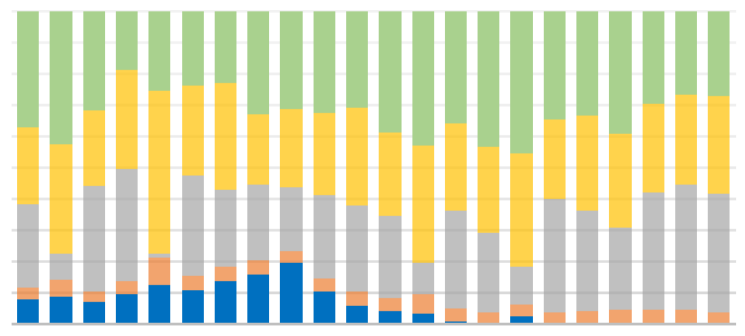

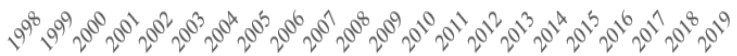

2(d) Australia

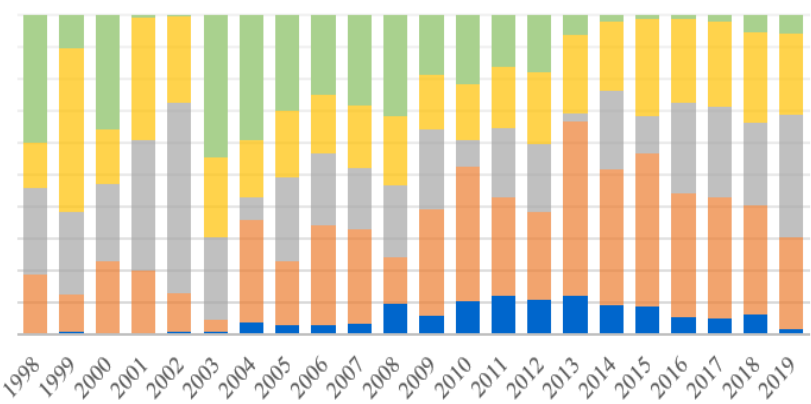

2(e) India

- Rubber $\square$ Cassava $\square$ Fruit $\square$ Vegetable $\square$ Herb

Figure 2: The TE scores from 1998 to 2019

The mean TE scores of Thai agricultural exports are shown in Figure 3. Empirically, the TE levels of Thai agricultural exports to the FTA partners are far below their estimated efficient ranks. Among the Thai - FTA trading partners, China and Japan had the highest export efficiencies with the same average $\mathrm{TE}$ at 0.48 . This is followed by India and New Zealand at 0.41 and 0.39 . Australia had the lowest one at 0.33 , in which rubber and cassava probably encountered certain burdens. The findings indicate that Thailand should adopt more FTA negotiations with the trading partners and support lenient rules of origin for export efficiency. Moreover, they should promote miscellaneous behind-the-border barriers to stimulate flows of goods that can improve the country's trade efficiency substantially. 
There is no guarantee that an FTA would cause shifts in a particular direction of free trade. The effects rely substantially on the negotiations and agreements (Asian Development Bank, 2008). In particular, Thailand operates with an outward-oriented strategy that engages in a pro-free-market competition. Policymakers understand the comprehensive and complicated manners of agreements and attempt to foster advantages while minimizing the potentially negative impacts.

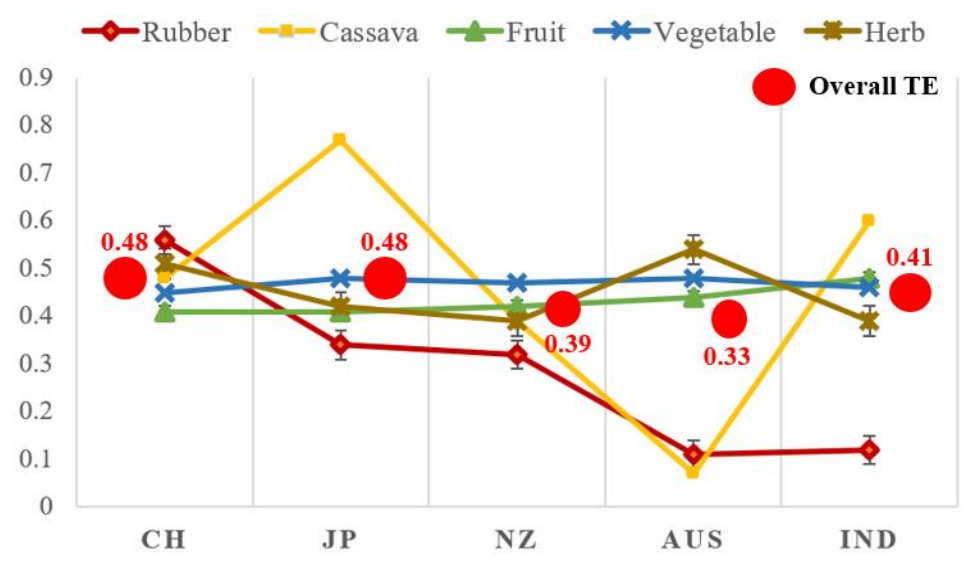

Figure 3: TE scores of Thai agricultural exports to FTA partners

\section{Conclusions and Policy Implications}

This study investigated the international trade efficiency levels of Thai agricultural exports of rubber, cassava, fruits, vegetables, and herbs with FTA trading partners, namely China, Japan, New Zealand, Australia, and India. We augmented the traditional GSFM by considering the dependency between two error elements: a non-negative error $(\mu)$, indicating the trade inefficiency, as well as asymmetric noise (v), indicating country-specific circumstances. The copulas including Gaussian, Student-t, and Farlie-Gumbel-Morgenstern copulas were constructed to deal with dependency structures. Furthermore, we applied a panel data framework to estimate the trade efficiencies, since this holds observations with diverse cross-sections and times. This method provides more information, more variability, and more efficiency during the studied period. The main findings can be summarized as follows:

- The Student t copula-based SFMs offer the best model specification to precisely evaluate the trade efficiency levels for Thailand and its FTA trading partners since this produced lower AIC and BIC than the other copula families. 
- The Thai-Australia trading partnership retains some obstacles to the export of agriculture commodities, in particular rubber and cassava. Hence, Thailand has remaining unused trade potential in this context.

-From the overall point of view, the Thai Government should intensively foster export efficiency for agriculture commodities by stimulation of structural reforms, as a comprehensive global resolution. It is not only the removal of tariffs and non-tariff barriers but also FTA facilitation and negotiating agreements. Policymakers must understand the manifold natures of a treaty and try to pursue advantages while minimizing disadvantages.

-To improve trade efficiency, the Thai government should increase several agricultural instruments to diversify risks in the international market. Moreover, it should substantially promote collaboration between the private sector and the government. The private sector can predicate either distinct barriers or best practices from the engagement in each market. Also, the government should diagnose various recommendations received from the private sector. The government sets a priority for those issuers that will affect Thailand's economy. Ultimately, these collaborations may improve Thai competitiveness and trade efficiency.

\section{Declarations}

Ethical approval and consent to participate (Not applicable)

Consent for publication (Not applicable)

\section{Competing interests}

The authors of the paper do not have any conflict of interest.

Availability of data and materials (Not applicable)

Funding (Not applicable)

\section{Authors' Contributions}

- Romyen, A. : Conceptualization, Methodology, Data Preparation, Data Curation, Formal Analysis, Statistic Program, Investigation, Writing, Supervision.

- Nunti, C. : Statistic Program, Coding of the Statistic Software Literature Reviews

- Neranon, P. : Coding of the Statistic Software, Visualization

All authors have read and agreed to the published version of the manuscript. 


\section{Acknowledgments}

We sincerely thank the Faculty of Economics, Prince of Songkla University, Thailand. Additionally, we thank the Publication Clinic, the Research and Development Office, Prince of Songkla University for the Enago Editing Service.

\section{Authors' Information}

1, * Ph.D., Department of Agribusiness Economics and Management, Faculty of Economics, Prince of Songkla University, Thailand. Email: arisara.r@psu.ac.th (* Corresponding Author)

2 Ph.D., Faculty of Economics, Chiang Mai University, Thailand. Email: chonradanunti@gmail.com

3 Assistant Professor, Department of Mechanical and Mechatronics Engineering, Faculty of Engineering, Prince of Songkla University, Thailand. Email: paramin.n@psu.ac.th

\section{References}

Anderson J E (2014) Trade, Size and Frictions: the Gravity Model. Mimeo Boston College. Retrieved January 22, 2020 from: https://www2. bc. edu/ anderson/GravityNotes. pdf

Baltagi B H (1995) Econometric Analysis of Panel Data. Econometric Theory, Wiley. 13(5): 747-754.

Boonyakunakorn P, Pastpipatkul P, Sriboonchitta S (2018) Thai Export Efficiency in AFTA: CopulaBased Gravity Stochastic Frontier Model with Autocorrelated Inefficiency. In Proceeding of the 6th International Symposium (457-466). Hanoi, Vietnam, March 15-17: IUKM 2018.

Chaney T (2011) The Gravity Equation in International Trade: An Explanation. PRELIMINARY AND INCOMPLETE, WORKING PAPER 19285, (1-28).

Chang P, Kaltani L, Loayza N V (2009) Openness can be good for growth: The role of policy complementarities. J. of Development Economics, 90 (1): 33-49.

Das A (2015) Copula-based Stochastic Frontier Model with Autocorrelated Inefficiency. Central European J.of Economic Modelling and Econometrics, 7(1): 111-126.

Dollar D (1992) Outward-oriented developing economies really do grow more rapidly: evidence from 95 LDCs, 1976-1985. Economic Development and Cultural Change, 40(3): 523-544.

Dollar D, Kraay A (2004) Trade, growth, and poverty. The Economic J., 114(493): 22-49.

Edwards S (1998) Openness, productivity and growth: what do we really know? The economic J., 108(447): 383-398.

Frankel J A, Romer D H (1999) Does trade cause growth? American Economic Review, 89(3): 379-399. 
Freund C, Bolaky B (2008) Trade, regulations and income. J.of Development Economics, 87 (2): 309321.

Harada K, Nishitateno, A (2021) Measuring trade creation effects of free trade agreements: Evidence from wine trade in East Asia. J. of Asian Economics, 74(101308): 1-10.

Harrison A (1996) Openness and growth: A time-series, cross-country analysis for developing countries. J.of development Economics, 48(2): 419-447.

Hur J, Park C P (2012) Do Free Trade Agreements Increase Economic Growth of the Member Countries? World Development. 40(7): 1283-1294.

Janas S S, Sahu T N, Pandey K D (2020) How far is FDI relevant to India's foreign trade growth? An empirical investigation. J. of Economic Structures, 9 (30): 2-19.

Kaliraja K P, Shand R T (1999) Frontier Production Functions and Technical Efficiency Measures. J.of Economic Surveys, 13(2). Blackwell Publishers.

Kuroiwa I (2021) Method of value chain mapping with international input-output data: application to the agricultural value chain in three Greater Mekong Subregion countries. J. of Economic Structures, 10(6): 1-23.

Rodriguez F, Rodrik D (2000) Trade policy and economic growth: a skeptic's guide to the cross-national evidence. NBER Macroeconomics Annual, 15(1): 261-325.

Rodrik D, Subramanian A, Trebbi F (2004) Institutions rule: the primacy of institutions over geography and integration in economic development. J.of Economic Growth, 9(2): 131-165.

Romyen A, Liu J, Sriboonchitta S (2019) Export-Output Growth Nexus Using Threshold VAR and VEC Models: Empirical Evidence from Thailand. Economies, 7(2): 1-16.

Roperto J D, Edgardo C (2014) Philippine Export Efficiency and Potential: An Application of Stochastic Frontier Gravity Model. Munich Personal RePEc Archive, paper No. 53580.

Sachs J D, Warner A, Åslund A, Fischer S (1995) Economic reform and the process of global integration. Brookings papers on economic activity, 1-118.

Santosa D W (2018) Does export promotion policy benefit for ASEAN economic development? International J.of Trade and Global Markets, 11(2): 1-12.

Tinbergen J (1962) Shaping the world economy: Suggestions for an international economic policy. New York: Twentieth Century Fund.

Wacziarg R, Welch K H (2008) Trade liberalization and growth: New evidence. The World Bank Economic Review, 22(2): 187-231. 
World Trade Organization (2003) Industrial Tariff Liberalization and the Doha Development Agenda. Development and Economic Research Division, Geneva, Switzerland.

World Trade Organization (2019) The protective effect of EU Agricultural Tariffs. The 2019 EU Trade Policy Review. 